\title{
Evaluasi dan Optimalisasi Instalasi Pengolahan Lumpur Tinja (IPLT) Talang Bakung Jambi
}

\author{
Reynaldo Purba ${ }^{1}$, Monik Kasman ${ }^{2 *}$, dan Peppy Herawati ${ }^{3}$ \\ ${ }^{1,2,3}$ Program Studi Teknik Lingkungan Universitas Batanghari \\ Jalan Slamet Riyadi, Broni, Kota Jambi \\ *correspondence email: monik.kasman@unbari.ac.id
}

\begin{abstract}
Jambi City has sewage treatment, namely Talang Bakung IPLT. The processing system in Talang Bakung IPL uses a pond system consisting of mud separator, anaerobic ponds, facultative ponds and maturation ponds and sludge drying tanks. This study aims to determine the performance and effectiveness of processing units in existing conditions and planning. The evaluation was carried out at each Talang Bakung installation unit (IPLT) on the performance of the processing unit and the processing quality of the inlet namely the mud separator unit to the maturation pond as the last processing unit under existing conditions (2017). Parameter checking in this study refers to LHK PERMEN No. 68 of 2016 concerning quality standards for domestic wastewater, namely pH, BOD, COD. TSS, Oil and fat, ammonia and Total Coliform. From the results of research, discussion and analysis, and referring to the research objectives, it can be concluded that: (1) there is still unused capacity (iddle capacity), (2) the design of Talang Bakung IPLT processing units is in accordance with design criteria, (3) the effectiveness of decreasing BOD, COD and TSS in each processing unit and overall > 60\%, (4) the concentration of pH, oil and fat, ammonia and total coliform decreased $>80 \%$ and already below the quality standard.
\end{abstract}

Keywords: IPLT, Feces, BOD, COD, TSS

\section{Pendahuluan}

Salah satu upaya yang dilakukan pemerintah guna meningkatkan kualitas pemukiman adalah dengan penyediaan sarana IPLT (Instalasi Pengolahan Lumpur Tinja). IPLT adalah instalasi pengolahan air limbah yang dirancang hanya menerima dan mengolah lumpur tinja yang diangkut melalui mobil (truk tinja) atau gerobak tinja. Lumpur tinja diambil dari unit pengolah limbah tinja seperti tangki septik dan cubluk tunggal ataupun endapan lumpur dari underflow unit pengolah air limbah lainnya. IPLT dirancang untuk mengolah lumpur tinja sehingga tidak membahayakan bagi kesehatan masyarakat dan lingkungan sekitarnya. Lumpur diolah menjadi lumpur kering yang disebut dengan cake dan air olahan (effluent) yang sudah aman dibuang atau dimanfaatkan kembali. Lumpur kering (cake) dapat dimanfaatkan menjadi pupuk dan air effluent dapat digunakan untuk keperluan irigasi (Kementerian PUPR, 2014 dalam Azizah, 2017).

IPLT dibangun pada tahun 1996 dan mulai dioperasikan pada tahun 1997. Kemudian pada tahun 2015 dilakukan optimasi dan rehabilitasi IPLT dengan penambahan unit SSC (Sludge Separation Chamber) dengan kapasitas 112 M3.

Pada tahun 2017 IPLT Talang Bakung telah melayani 11 kecamatan di Kotamadya Jambi melalui truk tinja milik pemerintahan kota dan swasta. Namun, keberadaan IPLT Talang Bakung belum diimbangi dengan pengoperasian yang optimal. Faktor penyebabnya dapat dilihat dari aspek teknis yang dilakukan di IPLT Talang Bakung meliputi kapasitas IPLT, timbulan lumpur tinja, kondisi eksisting unit pengolahan, sarana dan prasarana, dan tenaga kerja..

Pengoperasian unit SSC eksisting membutuhkan waktu yang lama untuk memisahkan endapan lumpur dari lumpur tinja hingga lumpur dapat diangkut dari bak SSC. Selain itu tidak adanya fasilitas laboratorium pada UPT IPLT Talang Bakung menyebabkan tidak optimalnya pemantauan rutin pada pengolahan air limbah pada IPLT. Berdasarkan observasi, pemeliharaan unit pengolahan saat ini masih belum optimal. Hal tersebut terlihat dari adanya sampah di unit-unit pengolahan IPLT. Adapun sampah yang ditemukan adalah sampah anorganik yang terbawa bersama lumpur tinja oleh truk tinja dan sampah organik dari tanaman di sekitar unit pengolahan.

Tujuan dari penelitian yang dilakukan yaitu : 1) Mengetahui kinerja masing-masing unit IPLT pada kondisi eksisting dan perencanaan; 2) Mengetahui efisiensi penurunan parameter masing-masing unit dan efisiensi total unit IPLT pada kondisi eksisting mengacu pada PERMEN LHK No. 68 Tahun 2016 tentang baku mutu air limbah domestik. 3)Mengoptimalisasi kinerja IPLT sesuai dengan kondisi perencanaan.

\section{Metode Penelitian}

Pada penelitian ini akan dilakukan evaluasi dengan studi kasus pada Instalasi Pengolahan Lumpur Tinja (IPLT) Talang Bakung Kota Jambi. Evaluasi dilakukan dengan menganalisa data-data primer dan sekunder. Metode penelitian dijelaskan pada Gambar 1.

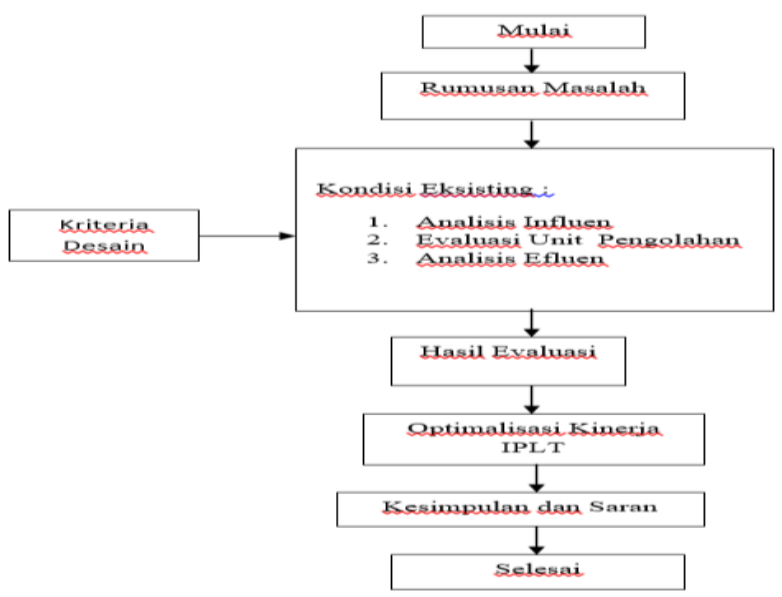

Gambar 1. Diagram Alir Penelitian 


\section{Hasil dan Pembahasan}

\subsection{Potensi Timbulan Lumpur Tinja Kota Jambi}

Menurut data BPS Kota Jambi, jumlah penduduk Kota Jambi pada tahun 2017 adalah 583.487 jiwa. Jika pelayanan IPLT diasumsikan $100 \%$ maka, potensi timbulan lumpur tinja Kota Jambi adalah :

$\mathrm{Q}=$ Jumlah Penduduk $\times$ Laju timbulan lumpur tinja $=583.487$ Jiwa $\times(0,5 / 1000) \mathrm{m} 3=291,74 \mathrm{~m} 3 /$ hari

Berdasarkan perhitungan potensi timbulan lumpur tinja diketahui timbulan lumpur tinja Kota Jambi dalam 1 (satu) hari adalah sebesar 291,74 m3/hari

Hasil paling besar terdapat pada lokasi I dengan tajuk/kerapatan pohon sedang dan yang paling kecil terjadi pada lokasi III, dimana jumlah vegetasi tidak terlalu mempengaruhi jumlah emisi CO2 di lokasi I.

\subsection{Kapasitas dan Debit IPLT \\ Kapasitas}

Kapasitas terpasang IPLT berdasarkan gambar rencana adalah 112,84 m3 dengan Q desain lumpur tinja harian sebesar 16,12 m3/hari. Namun berdasarkan perhitungan potensi timbulan lumpur tinja dapat dikatakan bahwa, timbulan lumpur tinja dalam satu hari lebih besar daripada kapasitas debit harian IPLT. IPLT Talang Bakung dalam 1 hari hanya dapat mengolah buangan lumpur tinja sebesar $(112,84 \mathrm{~m} 3 \div$ $291,74 \mathrm{~m} 3) \times 100 \%=38,6 \%$ dari timbulan lumpur tinja Kota Jambi.

\section{Analisis Debit}

Berdasarkan data sekunder dari Dinas Pekerjaan Umum Kota Jambi, debit lumpur tinja yang masuk ke IPLT Talang Bakung jangka waktu januari hingga oktober 2017 ditunjukan dalam tabel 1 .
Tabel 1. Debit Influen Lumpur Tinja Jangka Waktu Januari Oktober 2017

\begin{tabular}{cccc}
\hline No. & Bulan & Kubikasi $\left(\mathrm{M}^{3}\right)$ & $\begin{array}{c}\text { Rata-rata harian } \\
\left(\mathrm{M}^{3} / \text { hari }\right)\end{array}$ \\
\hline 1 & Januari & 190 & 6,13 \\
2 & Februari & 162 & 5,78 \\
3 & Maret & 186 & 6 \\
4 & April & 152 & 5,067 \\
5 & Mei & 180 & 5,80 \\
6 & Juni & 118 & 3,934 \\
7 & Juli & 208 & 6,701 \\
8 & Agustus & 130 & 4,193 \\
9 & September & 84 & 2,8 \\
10 & Oktober & 112 & 3,613 \\
\hline
\end{tabular}

Sumber : Dinas Pekerjaan Umum Kota Jambi, 2017

Berdasarkan perbandingan debit rata-rata harian terhadap kapasitas IPLT Talang Bakung, disimpulkan IPLT Talang Bakung mengalami iddle capacity (kapasitas tidak terpakai sebesar 31,017\%). Hal tersebut disebabkan oleh rendahnya kesadaran masyarakat tentang pengolahan limbah tinja dan minimnya pengetahuan masyarakat tentang IPLT, sehingga IPLT Talang Bakung belum dimanfaatkan dengan maksimal.

\section{Evaluasi Unit Pengolahan}

Unit-unit yang digunakan untuk mengolah lumpur tinja di IPLT Talang Bakung terdiri dari bak SSC atau bak pemisah lumpur dan rangkaian kolam stabilisasi berupa: kolam anaerobik, kolam fakultatif dan kolam maturasi serta bak pengering lumpur yang berfungsi untuk mengeringkan padatan lumpur. Selanjutnya air limbah hasil pengolahan IPLT disalurkan ke wetland atau rawa buatan yang berada dibelakang kawasan IPLT.

\section{Bak SSC}

Desain eksisting Bak SSC IPLT Talang Bakung telah sesuai dengan kriteria desain. Berdasarkan pengamatan di lapangan, permasalahan yang terdapat pada Bak SSC adalah adanya kompartemen yang tidak terpakai dikarenakan pengoperasian yang tidak sesuai SOP (Standar Operating procedure). Selain itu kondisi Bak SSC terdapat sampah plastik yang terbawa dari truk tinja.

Tabel 2. Analisis Desain SSC (Sludge Separation Chamber)

\begin{tabular}{clcccc}
\hline \multirow{2}{*}{ No. } & \multicolumn{1}{c}{ Parameter } & Satuan & Kriteria Desain* & Desain Eksisting & Keterangan \\
\hline 1 & Waktu pegeringan cake & Hari & $5-12$ & 11 & Sesuai \\
2 & Waktu pengambilan cake matang & Hari & $1-3$ & 1 & Sesuai \\
3 & Ketebalan lumpur (cake) & Cm & $30-50$ & 40 & Sesuai \\
4 & Tebal lapisan pasir & Cm & $20-30$ & 20 & Sesuai \\
5 & Tebal lapisan kerikil & Cm & $20-30$ & 30 & Sesuai \\
6 & Bar Screen & - & ada & ada & Sesuai \\
\hline
\end{tabular}

Ket : *) Joni Hermana, 2008 dalam Ahmad Sadeli, 2015

\section{Kolam Anaerobik}

Tabel 3. Analisis Desain Kolam Anaerob

\begin{tabular}{|c|c|c|c|c|c|}
\hline No & Parameter & Satuan & Kriteria Desain & Desain Eksisting & Ket \\
\hline 1 & Waktu detensi & hari & $\begin{array}{c}20-50 \\
\text { (Thcobanoglous,1991 dalam Wardhana, 2009) }\end{array}$ & 54 & Tidak sesuai \\
\hline 2 & Kedalaman & $\mathrm{m}$ & $\begin{array}{c}2-5 \\
\text { (Thcobanoglous,1991 dalam Wardhana, 2009) }\end{array}$ & 3 & Sesuai \\
\hline 3 & Rasio panjang dan lebar & $\%$ & $\begin{array}{c}(2-4): 1 \\
\text { (Dept. PU Dirjen Cipta Karya, } 1998 \text { dalam } \\
\text { Wardhana, 2009) }\end{array}$ & $\begin{array}{l}16 \mathrm{~m}: 21 \\
1: 1,3\end{array}$ & Tidak sesuai \\
\hline
\end{tabular}




\begin{tabular}{cccccc}
4 & Tinggi jagaan & $\mathrm{m}$ & $0,3-0,5$ & 0,5 & Sesuai \\
5 & Efisiensi BOD & $\%$ & (Dept. PU Dirjen Cipta Karya, 1998) & $\geq 70 \%$ & 78,5 \\
\hline
\end{tabular}

Berdasarkan tabel 3 diketahui kolam anaerobik eksisting masih belum memenuhi beberapa kriteria desain, yaitu waktu detensi dan rasio panjang dan lebar kolam. Selain itu permasalahan yang terjadi pada kolam anaerob ini adalah terdapat sampah yang terbawa dari Bak SSC.

\section{Kolam Fakultatif}

Tabel 4. Analisis Desain Kolam Fakultatif

\begin{tabular}{clclcc}
\hline No & Keterangan & Kriteria Desain & \multicolumn{1}{c}{ Sumber } & Desain Eksisting & Hasil Analisis \\
\hline 1 & Panjang : Lebar & $2-4: 1$ & Dept. PU Dirjen Cipta Karya 1999 & $35: 15$ & $3: 1 \mathrm{~m}$ \\
2 & Kedalaman Air & $1,2-2,4 \mathrm{~m}$ & Tchobanoglous 1991 & $1,5 \mathrm{~m}$ & Memenuhi \\
3 & Tinggi Jagaan & $0,3-0,5 \mathrm{~m}$ & Dept. PU Dirjen Cipta Karya 1999 & $0,5 \mathrm{~m}$ & Memenuhi \\
4 & Waktu detensi & $5-30$ hari & Tchobanoglous 1991 & 98 hari & Tidak memenuhi \\
5 & Efisiensi BOD & $\geq 70 \%$ & (Dept. PU Dirjen Cipta Karya, 1999) & $63,4 \%$ & Tidak memenuhi \\
\hline
\end{tabular}

Berdasarkan tabel 4 diatas dapat diketahui desain kolam fakultatif IPLT Talang Bakung telah memenuhi kriteria desain. Berdasarkan pengamatan visual terhadap kolam fakultatif IPLT Talang Bakung, ditemukan banyak padatan dan sampah yang terbawa dari unit kolam anaerob. Hal tersebut menandakan bahwa pemeliharaan terhadap unit kolam fakultatif belum optimal, selain itu pada rangkaian kolam kedua dan ketiga ditemukan tumpukan alga yang menutupi permukaan kolam. Kondisi tersebut dapat menyebabkan terganggunya proses aerobik pada kolam, selain itu banyaknya alga dapat mnyebabkan pendangkalan kolam atau eutrofikasi.

\section{Kolam Maturasi}

Berdasarkan pengamatan terhadap kolam maturasi IPLT Talang Bakung, terlihat sebagian permukaan kolam tertutup oleh alga, selain itu keberadaan tumbuhan kelapa sawit di sekitar kolam menghalangi sinar matahari ke kolam maturasi tersebut. Hal tersebut dapat mempengaruhi proses penguraian bakteri patogen oleh sinar matahari. Pemeliharaan kolam maturasi saat ini masih belum optimal, hal tersebut terlihat dari adanya padatan dan sampah dari tanaman di sekeliling kolam.

Tabel 5. Analisis Desain Kolam Maturasi

\begin{tabular}{|c|c|c|c|c|c|}
\hline No & Keterangan & $\begin{array}{c}\text { Kondisi } \\
\text { Optimum }\end{array}$ & Sumber & $\begin{array}{c}\text { Kondisi } \\
\text { Lapangan }\end{array}$ & Hasil Analisis \\
\hline 1 & Panjang : Lebar & $2-4: 1$ & Dept. PU Dirjen Cipta Karya 1999 & $3: 1 \mathrm{~m}$ & Memenuhi \\
\hline 2 & Kedalaman Air & $0,9-1,5 \mathrm{~m}$ & Tchobanoglous 1991 & $1 \mathrm{~m}$ & Memenuhi \\
\hline 3 & Tinggi Jagaan & $0,3-0,5 \mathrm{~m}$ & Dept. PU Dirjen Cipta Karya 1999 & $0,5 \mathrm{~m}$ & Memenuhi \\
\hline 4 & Waktu detensi & $5-20$ hari & Tchobanoglous 1991 & 30 hari & Tidak memenuhi \\
\hline 5 & Efisiensi BOD & $\geq 70 \%$ & Dept. PU Dirjen Cipta Karya 1999 & $21,12 \%$ & Tidak memenuhi \\
\hline 6 & Efisiensi Total Coliform & $\geq 90 \%$ & Dept. PU Dirjen Cipta Karya 1999 & $18,2 \%$ & Tidak memenuhi \\
\hline
\end{tabular}

Berdasarkan tabel 5 dapat diketahui bahwa kolam maturasi eksisting sudah memenuhi ketentuan kriteria desain standar. Akan tetapi pemeliharaan pada kolam maturasi eksisting belum berjalan dengan baik, berdasarkan pengamatan, terlihat sampah daun dan biji dari tanaman sawit yang berada dipinggir kolam, sampah tersebut dapat mengganggu proses pengolahan yaitu dapat menyumbat aliran pada unit ini.

\section{Bak Pengering Lumpur / SDB (Sludge Drying Bed)}

Bak pengering lumpur di IPLT Talang Bakung dapat menampung lumpur sebesar 300 M3 dengan ukuran; Panjang 20m, Lebar 10 meter, ketinggian dinding 1,5 m dan tinggi jagaan $20 \mathrm{~cm}$.

SDB (Sludge Drying Bed) bak pengering lumpur merupakan proses pengeringan padatan lumpur dari unit-unit pengolahan sebelumnya yang sudah setengah kering dan sekaligus proses desinfeksi mikroorganisme terkandung dalam lumpur melalui sinar matahari (ultra violet).

Berikut ini adalah data teknis unit SDB eksisting:

Konstruksi : Beton

Bentuk : Persegi panjang

Panjang : $20 \mathrm{~m}$

\section{Lebar $\quad: 10 \mathrm{~m}$ \\ Tinggi $\quad: 1,5 \mathrm{~m}$ \\ Tinggi jagaan $: 0,2 \mathrm{~m}$}

Secara umum, kondisi fisik unit-unit pengolahan yang ada pada instalasi (IPLT) Talang Bakung ini dapat dikatakan dalam kondisi baik. Namun demikian, pengoperasian IPLT Talang Bakung saat ini masih belum optimal, beberapa indikator yang dapat dilihat dalam hal ini di antaranya :

- Pengoperasian instalasi tidak sesuai SOP

- Tidak ada peralatan monitoring kualitas air limbah

- Tidak ada data hasil monitoring kualitas air limbah yang dihasilkan baik yang bersifat mingguan maupun bulanan di IPLT.

\section{Analisis Efluen}

Analisis efisiensi total untuk setiap parameter mengacu pada peraturan yang telah ditetapkan oleh PERMEN LHK No. 68 Tahun 2016 tentang baku mutu air limbah, yaitu pH, BOD, COD, TSS, Minyak dan Lemak, Amoniak, Total Coliform, dan penambahan 2 (dua) parameter limbah B3 yaitu $\mathrm{Hg}$ dan Cr. Hasil analisis laboratorium ditampilkan pada Tabel 6. 
Tabel 6. Analisis Efisiensi Total IPLT Talang Bakung

\begin{tabular}{clcccccc}
\hline No. & \multicolumn{1}{c}{ Parameter } & Satuan & Influen/ ${ }^{*}$ SSC & Efluen & Efisiensi $(\%)$ & Baku Mutu $^{* *}$ & Keterangan \\
\hline 1 & TSS & $\mathrm{mg} / \mathrm{L}$ & 11820 & 90 & 99 & 30 & Tidak memenuhi \\
2 & $\mathrm{pH}$ & - & 6,50 & 6,81 & - & $6-9$ & Memenuhi \\
3 & BOD 5 & $\mathrm{mg} / \mathrm{L}$ & 12090 & 56 & 99 & 30 & Tidak memenuhi \\
4 & COD & $\mathrm{m} / \mathrm{L}$ & 18754 & 158 & 99 & 100 & Tidak memenuhi \\
5 & Minyak \& Lemak & $\mathrm{mg} / \mathrm{L}$ & 51 & 2,2 & 95 & 5 & Memenuhi \\
6 & Amoniak & $\mathrm{mg} / \mathrm{L}$ & 9,34 & 1,07 & 88 & & Memenuhi \\
7 & Merkuri $(\mathrm{Hg})$ & $\mathrm{mg} / \mathrm{L}$ & 0,00033 & $2 \times 10^{-4}$ & 39 & - & \\
8 & Chromium $(\mathrm{Cr})$ & $\mathrm{mg} / \mathrm{L}$ & $<0,001$ & $<0,001$ & - & & \\
9 & DO & $\mathrm{mg} / \mathrm{L}$ & 0 & 2,04 & & 3000 & memenuhi \\
10 & Total Coliform & Jumlah/100 & 17000 & 2700 & 84 & & \\
\hline
\end{tabular}

Ket : ${ }^{*}$ Data Primer, 2018; ${ }^{* *}$ PERMEN LHK No. 68 Tahun 2016

Efisiensi total dihitung berdasarkan kualitas influent yang masuk ke unit pengolahan dan kualitas efluen yang telah di olah di IPLT Talang Bakung. Hal ini bertujuan untuk mengetahui kinerja IPLT secara keseluruhan.

Secara umum proses pengolahan air limbah pada IPLT Talang Bakung berdasarkan hasil pemeriksaan karakteristik air limbah pada bulan Januari 2018 sudah berjalan cukup optimal. Hal ini ditandai dengan efisiensi pengolahan yang memenuhi kriteria desain efisiensi pengolahan proses biologis yaitu $\geq 70 \%$.

Akan tetapi beberapa parameter pada efluen IPLT Talang Bakung masih belum memenuhi baku mutu air limbah menurut PERMEN LHK No. 68 Tahun 2016. Dimana parameter yang tidak memenuhi baku mutu antara lain : BOD5, COD dan TSS, sedangkan parameter yang memenuhi baku mutu antara laim : pH, Minyak dan Lemak, Amoniak dan Total Coliform.

\subsection{Optimalisasi Kapasitas}

Berdasarkan analisis potensi timbulan lumpur tinja, Kota Jambi dengan Jumlah penduduk sebesar 583.487 (BPS Kota Jambi, 2017) berpotensi menghasilkan lumpur tinja sebesar 291,74 m3/hari. Sementara kapasitas terpasang IPLT Talang Bakung saat ini hanya sebesar 112,84 m3 dan debit harian sebesar 16,12 m3.

Akan tetapi saat ini IPLT Talang Bakung belum maksimal dimanfaatkan masyarakat Kota Jambi, hal ini terlihat dengan adanya kapasitas tidak terpakai sebesar $31,017 \%$. Berdasarkan debit influen lumpur tinja jangka waktu Januari sampai Oktober 2017 yang tertera pada tabel 1. Ratarata debit influen yang masuk ke IPLT hanya sebesar 5m3/hari. Kesadaran masyarakat terhadap pentingnya pengolahan limbah tinja serta kurangnya pengetahuan masyarakat terhadap keberadaan dan fungsi IPLT menjadi salah satu penyebab kurang optimal nya pemanfaatan IPLT.

Optimalisasi dapat dilakukan dengan meningkatkan pengetahuan masyarakat tentang pentingnya pengolahan limbah tinja melaui sosialisasi dan kampanye tentang kegunaan IPLT sehingga dapat meningkatkan partisipasi masyarakat dalam memanfaatkan IPLT.

\section{Unit Pengolah}

\section{Bak SSC (Solids Separation Chamber)}

Agar unit SSC IPLT Talang Bakung beroperasi dengan optimal dan berkelanjutan maka dari evaluasi unit SSC diatas dapat di rumuskan tata cara pengoperasian unit SSC sebagai berikut:
Pengisian 1 kompartemen bak SSC dilakukan selama 2 hari dengan debit per hari sebesar 16,12 m3/hari atau sama dengan 4 unit truk berkapasitas $4 \mathrm{~m} 3$.

1 bak SSC hanya digunakan untuk pengisian lumpur tinja dalam 2 (dua) hari. Pengisian selanjutnya dilakukan pada kompartemen berikutnya.

Selanjutnya dilakukan proses stabilisasi lumpur selama 13 hari, dengan waktu tunggu 12 hari untuk proses dekantasi (penyaringan) dan pengeringan dan 1 hari untuk pengangkutan cake lumpur dan pembersihan bak. Sehingga bak dapat digunakan lagi.

Pada hari ke-14 (empat belas) cake lumpur pada bak SSC sudah harus di angkut/dibersihkan Sehingga bak dapat digunakan lagi keesokan harinya.

\section{Kolam Anaerob}

Untuk mengoptimalkan kinerja kolam anaerobik maka diperlukan beberapa perbaikan antara lain: pemasangan pipa penguras lumpur dan dan pembersihan sampah organik dan anorganik pada kolam

\section{Kolam Fakultatif}

Pemasangan pipa penguras lumpur dan penambahan unit pompa untuk menyedot endapan lumpur serta pembersihan alga dan buih scum pada permukaan kolam.

\section{Kolam Maturasi}

Tanaman kelapa sawit di sekitar tanggul kolam maturasi menghalangi penetrasi cahaya matahari pada kolam, sehingga perlu di tebang atau diganti dengan tanaman pendek (tanaman perdu).

Buih (scum) dan alga pada kolam fakultatif maturasi harus dibersihkan secara berkala agar tidak mengganggu proses pengolahan pada kolam

\section{Kesimpulan}

Desain Unit-unit pengolahan IPLT Talang Bakung sudah memenuhi kriteria desain, akan tetapi operasional dan pemeliharaan pada unit-unit pengolahan belum berjalan dengan baik.

Berdasarkan nilai influen dan efluen, efisiensi total dari IPLT untuk menurunkan kadar TSS adalah $99 \%$, BOD 99\%, COD 99\%, Minyak dan Lemak 95\%, Amoniak 88\%, dan Total Coliform $84 \%$. Kualitas efluen IPLT, parameter yang telah memenuhi baku mutu air limbah domestik menurut PERMEN LHK No. 68 Tahun 2016 adalah : pH, Minyak dan Lemak, Amoniak dan Total Coliform. Sedangkan parameter yang belum memenuhi baku mutu adalah: BOD, COD dan TSS. 
Optimalisasi dilakukan dengan penambahan SOP atau petunjuk pengoperasian unit IPLT; pembekalan kepada tenaga kerja mengenai operasional IPLT agar operasional IPLT dapat berjalan sesuai prosedur; Penambahan fasilitas laboratorium atau tenaga laboratorium di dalam kawasan IPLT, sehingga pemantauan kualitas pengolahan tiap unit dapat berlangsung secara berkala; dan penambahan unit pompa untuk menguras endapan lumpur yang terakumulasi pada unit pengolahan.

\section{Daftar Pustaka}

Keputusan Menteri Lingkungan Hidup dan Kehutanan No. 68 Tahun 2016 Tentang Baku Mutu Air Limbah Domestik Standar Teknis, (1998). CT/AL/Re - TC/003/98, Jakarta: KEMENPU RI.

Mara, Duncan. 2003. Domestic Wastewater Treatment in Developing Countries, UK. Earthscan.

Helmi Haki dan Dwi Oktarina, 2013. Perencanaan Instalasi Pengolahan Lumpur Tinja Sistem Kolam Kota Palembang. Palembang : Universitas Sriwijaya

Irawan, Wisnu Wardhana, Wina Karunia, 2009. Evaluasi dan Optimalisasi Instalasi Pengolahan Limbah Tinja Kota Pekalongan. Jurnal Presipitasi.

Department of Environment \& Natural Resorces, Phillipine, 2007 dalam

Departemen PU, 1999. Tata Cara Perencanaan Instalasi Lumpur Tinja Sistem Kolam. Jakarta: Departemen Pekerjaan Umum Direktorat Jendral Cipta Karya

Sugiharto. 1987. Dasar-dasar Pengelolaan Air Limbah. Penerbit Universitas Indonesia. Jakarta

Mara, Duncan. 2001. Pengolahan Air Limbah di Daerah Iklim Panas (Terjemahan). ITB. Bandung

Metcalf dan Eddy Inc. 1991. Wastewater Engineering : Treatment, Disposal, Reuse. New York : McGraw-Hill.

Varon, Miguel 2004. Waste Stabilisation Ponds. IRC International Water and Sanitation centre

Soeparman, H.M dan Suparmin. 2002. Pembuangan Tinja dan Limbah Cair, Suatu Pengantar. Buku Kedokterna EGC: Jakarta 